MICHAEL W. L. ELSBY

University of Edinburgh

BART HOBIJN

Federal Reserve Bank of San Francisco

AYŞEGÜL ŞAHIN

Federal Reserve Bank of New York

ROBERT G. VALLETTA

Federal Reserve Bank of San Francisco

\title{
The Labor Market in the Great Recession- An Update to September 2011
}

ABSTRACT Since the end of the Great Recession in mid-2009, the unemployment rate has recovered slowly, falling by only 1 percentage point from its peak by September 2011. We find that the lackluster labor market recovery can be traced in large part to weakness in aggregate demand; only a small part seems attributable to increases in labor market frictions. This continued labor market weakness has led to the highest level of long-term unemployment in the postwar period and a blurring of the distinction between unemployment and nonparticipation in the labor force. We show that flows from nonparticipation to unemployment are important for understanding recent changes in the duration distribution of unemployment. Simulations that account for these flows suggest that the labor market is unlikely to be subject to high levels of structural long-term unemployment after aggregate demand recovers.

n the Spring 2010 volume of the Brookings Papers, we provided an analysis of U.S. labor market developments in the most recent recession (Elsby, Hobijn, and Şahin 2010). We documented that, from the perspective of a wide range of labor market outcomes, the 2007-09 recession caused the deepest labor market downturn in the postwar era. Here we update that earlier work and provide new analyses and results regarding the extent and persistence of long-term unemployment in the aftermath of the recession.

Section I provides a summary update of our original work, focusing on indicators of labor market adjustment such as the Okun's Law relationship 
and the Beveridge curve. We also discuss recent research regarding the implications of these indicators for the extent of structural unemployment and conclude that it appears to be limited. Section II extends our earlier analyses by describing a set of new facts about unemployment inflows and outflows, which determine the path of the unemployment rate and its duration distribution. We document a sharp increase since the beginning of the recession in the incidence of measured monthly inflows to unemployment at reported durations that substantially exceed 1 month. These inflows appear to reflect a rising tendency for respondents to report the elapsed time since they first started searching rather than continuous periods spent in active search. On the basis of this more complete characterization of net flows, in section III we update the simulation of unemployment dynamics presented in Elsby and others (2010). The results indicate that long-term unemployment will largely dissipate if exit rates for the short-term unemployed recover, reinforcing our conclusion that the current extent of structural unemployment is quite limited.

\section{Update on Labor Market Adjustment}

As we documented in Elsby and others (2010), the labor market downturn that accompanied the 2007-09 recession was the most severe of the postwar era, and the subsequent recovery has been tentative and uneven. The most adversely affected groups include men in general as well as younger workers, less educated workers, and workers belonging to ethnic minorities. Starting in early 2010, labor market conditions have begun to recover slowly. The unemployment rate, which peaked at 10.1 percent, fell to 9.0 percent as of September 2011, still 4.6 percentage points above its prerecession low. Of the groups that experienced larger increases in their unemployment rates during the recession, most-including men, younger workers, and Hispanics - have since seen relatively larger declines in their unemployment rates (table 1). ${ }^{1}$

Elsby and others (2010) showed that the nature of labor market adjustment until mid-2009 displayed a notable resemblance to that observed in past severe downturns. Starting in 2009, however, indicators of real activity and the labor market began to diverge from past patterns. We summa-

1. In table 1 the labeled "recession" period corresponds to the incidence of rising unemployment rather than the National Bureau of Economic Research's recession dating. Two important exceptions to the patterns noted in the text are workers with less than a high school education and black workers. Workers without a high school diploma saw only a 0.8-percentage-point decline in their unemployment rate after a huge, 8.3-percentage-point rise during the recession. And following its initial surge, the unemployment rate of black workers has increased further, by 0.2 percentage point. 
Table 1. Changes in Unemployment Rates by Sex, Age, Education, and Race, 2007-11

\begin{tabular}{|c|c|c|c|}
\hline \multirow[b]{2}{*}{ Group } & \multirow[b]{2}{*}{$\begin{array}{l}\text { Prerecession level } \\
(2007 Q 2, \text { percent })\end{array}$} & \multicolumn{2}{|c|}{ Change (percentage points) } \\
\hline & & $\begin{array}{c}\text { Recession } \\
(2007 Q 2-2009 Q 4)\end{array}$ & $\begin{array}{c}\text { Recovery } \\
(2009 Q 4-2011 Q 3)\end{array}$ \\
\hline All workers & 4.5 & 5.4 & -0.8 \\
\hline \multicolumn{4}{|l|}{ Sex } \\
\hline Male & 4.6 & 6.5 & -1.6 \\
\hline Female & 4.4 & 4.3 & -0.2 \\
\hline \multicolumn{4}{|l|}{ Age } \\
\hline $16-24$ & 10.3 & 8.7 & -1.6 \\
\hline $25-54$ & 3.6 & 5.3 & -0.8 \\
\hline 55 and over & 3.1 & 3.9 & -0.3 \\
\hline \multicolumn{4}{|l|}{ Education } \\
\hline $\begin{array}{l}\text { Less than high } \\
\text { school diploma }\end{array}$ & 6.8 & 8.3 & -0.8 \\
\hline High school & 4.2 & 6.5 & -1.2 \\
\hline Some college & 3.5 & 5.3 & -0.5 \\
\hline $\begin{array}{l}\text { College degree or } \\
\text { higher }\end{array}$ & 2.0 & 2.8 & -0.5 \\
\hline \multicolumn{4}{|l|}{ Race or ethnicity } \\
\hline White & 4.0 & 5.2 & -1.2 \\
\hline Black & 8.4 & 7.6 & 0.2 \\
\hline Hispanic & 5.6 & 7.2 & -1.5 \\
\hline
\end{tabular}

Source: Bureau of Labor Statistics.

rized this divergence in the context of Okun's Law and the Beveridge curve and concluded that labor market conditions were weaker than implied by historical relationships between real activity and the labor market. Since then, however, official data for both GDP and the job openings rate for the recession period have been revised downward. In addition, the recovery in GDP and job openings slowed considerably in the first half of 2011, while the unemployment rate fell by about a percentage point. These developments brought the Okun's Law relationship in line with historical observations and narrowed the divergence in the Beveridge curve relationship (see figures $\mathrm{A} 1$ and $\mathrm{A} 2$ in the accompanying web appendix). ${ }^{2}$

Even though measures of real activity and of the labor market are now better aligned than they were in late 2009, recent observations on unemployment and job vacancies imply a rightward shift in the Beveridge curve of around 2.7 percentage points (figure A3 in the online appendix).

2. Online appendixes for papers in this volume can be accessed at the Brookings Papers website, www.brookings.edu/economics/bpea.aspx, under "Past Editions." 
A search-and-matching model that incorporates incentives for vacancy creation indicates that this rightward shift is consistent with an increase in the natural rate of unemployment of about 0.5 to 1.5 percentage points (see Barnichon and others 2010 and Daly and others forthcoming). This shift and the implied increase in the natural rate have been interpreted by us and others as evidence of the growing importance of structural factors in the persistently high unemployment rate (see, for example, Kocherlakota 2010). In Elsby and others (2010) we identified some potential causes of this deviation and evaluated three factors: skill mismatch, geographic mismatch arising from house lock (unwillingness or inability to sell one's home in a weak housing market), and emergency unemployment compensation.

Since early 2010, a substantial amount of research has addressed the quantitative importance of these channels. Our view, which is informed by reviewing the recent literature as well as some of our own work, can be summarized as follows:

-Skill mismatch likely has contributed about 1 percentage point to the increase in the unemployment rate, with estimates ranging from about 0.25 to 1.75 percentage points (Barnichon and Figura 2011, Estevão and Tsounta 2011, Daly and others forthcoming, Şahin and others 2011). However, available evidence suggests that the increase in unemployment that can be attributed to skill mismatch is not structural. The paper by Şahin and others studies a range of measures of mismatch, which reveal imbalances between vacancy and unemployment shares across sectors and occupations. Although these measures rose from 2007 until the end of the recession in mid-2009, they have declined significantly since then, suggesting that the impact of mismatch will largely disappear as the recovery proceeds. This pattern is consistent with dispersion in the sensitivity of sectoral activity to aggregate demand fluctuations (see, for example, Abraham and Katz 1986), but further research is needed to study the deep causes of mismatch.

- The role of geographic mismatch and the house-lock mechanism has been quantitatively negligible (Daly and others forthcoming, Molloy, Smith, and Wozniak 2010, Şahin and others 2011, Valletta 2010). The observation that the interstate migration rate declined during the recession was cited by some as motivating evidence for the importance of geographic mismatch. However, Greg Kaplan and Sam Schulhofer-Wohl (2010) have shown that the significant drop reported in the annual interstate migration rate between 2005 and 2006 in the Current Population Survey was a statistical artifact arising from the procedure that the Census 
Bureau used to handle missing data. The corrected data show that interstate migration has been trending downward for many years. Relative to that trend, there was no additional decrease in interstate migration during December 2007 to June 2009.

-Recent research has shown that emergency unemployment compensation (EUC) has likely had an impact on the natural rate of unemployment. Although estimates range from 0.3 to 3 percentage points, most studies find an effect of around 1 percentage point or less (see Aaronson, Mazumder, and Schecter 2010, Farber and Valletta 2011, Fujita 2011, Nakajima 2011, Rothstein, this volume, and Valletta and Kuang 2010).

To summarize, recent research indicates that skill mismatch and EUC have contributed to the deviation in the Beveridge curve. However, because this deviation has occurred at very low levels of vacancies, it is difficult to separate shifts in the curve that reflect an increase in matching frictions from short-term cyclical adjustments back toward the curve's initial position; at low vacancies, along the flat portion of the curve, small increases in vacancies imply a large deviation from the prior position of the curve. The evidence cited above suggests that the cyclical component has been much more important than the increase in frictions, and that the latter will dissipate as the labor market recovery progresses and the EUC extensions expire and are not renewed.

The continued weakness of the labor market thus appears mainly to be due to the continued shortfall in aggregate demand. The modest recovery in labor demand has been too weak to generate a substantial decline in the unemployment rate.

An ongoing development that appears at odds with our claim of limited matching frictions is the rise in long-term unemployment to record levels; the problem has intensified rather than improved during the 2 years since the recession ended. This can be seen from figure 1, which breaks the aggregate unemployment rate series down into six duration groups. As of July 2011, 4 percent of the labor force reported that they had been unemployed for more than 6 months, with about three-quarters of those unemployed for more than a year. The extent and persistence of long-term unemployment raises the concern that the United States might develop a long-term unemployment problem of the type that many European countries experienced after the severe recessions of the 1970s and 1980s (referred to as "Eurosclerosis"). However, in the next two sections we provide new evidence, based on an updated and extended analysis of net unemployment flows and simulations of the resulting unemployment dynamics, indicating that the risk of "Amerisclerosis" is small. 
Figure 1. Unemployment Rate by Duration, January 1994-July 2011ª

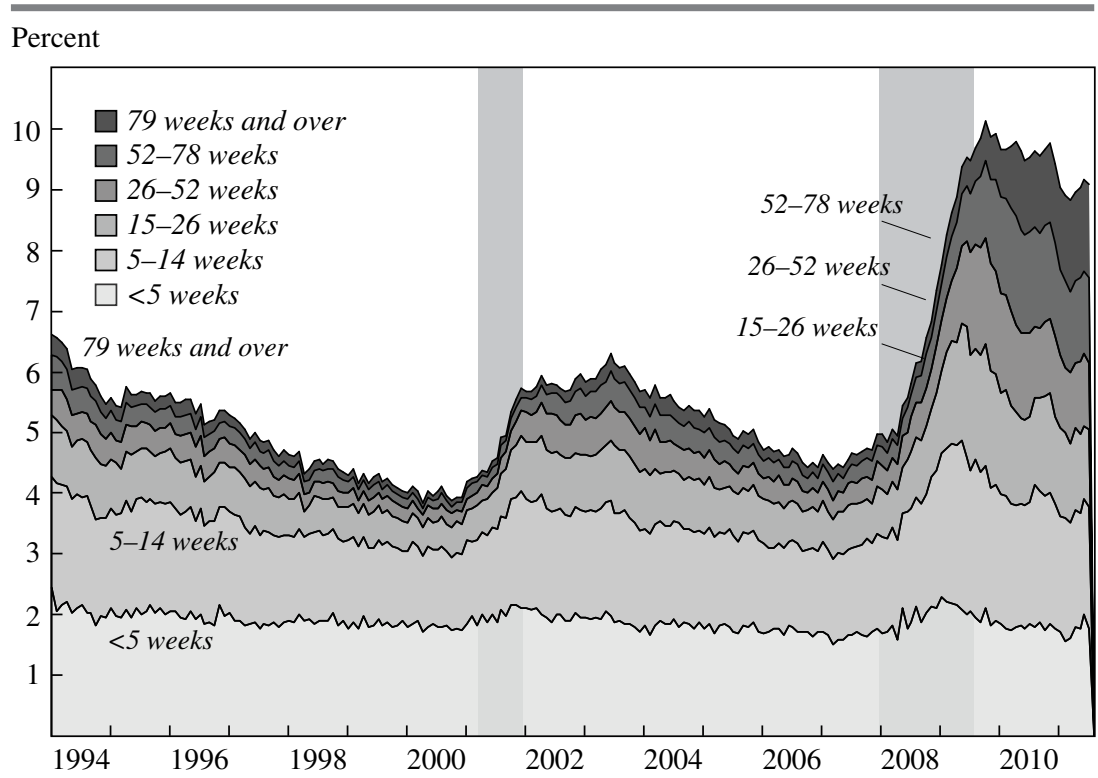

Sources: Bureau of Labor Statistics, Current Population Survey, and authors' calculations. a. Seasonally adjusted monthly observations. Shaded columns indicate recessions.

\section{Unemployment Inflows and Outflows Reconsidered}

In Elsby and others (2010) we used a labor market flows framework to discuss trends in the labor market during the Great Recession. A first clue to the potential sources of recent developments in the unemployment rate can be gleaned from an anomaly that has emerged in the behavior of two leading measures of these unemployment flows.

The first measure constructs flow transition probabilities from the longitudinally matched individual-level data in the Current Population Survey (CPS). For example, the unemployment-to-employment transition probability can be estimated using these data by computing the fraction of the unemployed in a month who report that they are employed in the following month's survey. Estimates of these aggregate transition probabilities for 1990 onward are available from the Bureau of Labor Statistics (BLS 2008), and pre-1990 estimates have been made available by Robert Shimer (2007). A drawback of these estimated flows is that they appear to contain a large number of spurious transitions, especially between unemploy- 
ment and nonparticipation (see Poterba and Summers 1995 and references therein for a discussion).

A second measure of labor market flows can be inferred from the reported duration structure of unemployment (Perry 1972, Shimer 2007). This measure estimates the outflow rate from unemployment using crosssectional data on the stock of unemployed workers, $u_{t}$, and the number unemployed for less than 5 weeks, $u_{t}^{<5 w}$, rather than longitudinal microdata on the flows. Using these data, Shimer (2007) computes the unemployment outflow hazard according to

$$
f_{t}=-\left[\ln \left(u_{t+1}-u_{t+1}^{<5 w}\right)-\ln \left(u_{t}\right)\right] .
$$

Shimer's outflow hazard can be interpreted as follows. First, one calculates the fraction of those unemployed this month who are still unemployed the next month. If all inflows into unemployment consist of persons who report a duration of unemployment shorter than 5 weeks, then this fraction equals the number of persons unemployed next month, $u_{t+1}$, minus those unemployed next month with a duration of unemployment shorter than 5 weeks, $u_{t+1}^{<5 w}$, expressed as a fraction of the number of currently unemployed, $u_{t}$ Second, one transforms this 1-month unemployment "survival" rate into a continuous-time outflow hazard. This is the unemployment outflow measure that we used for the majority of the analysis in Elsby and others (2010).

Figure 2 displays Shimer's estimate of the outflow hazard together with the unemployment-to-employment transition rate, where each is plotted as a logarithmic deviation from its respective historical mean. As we noted in our original paper, historically these two measures have moved very closely together over the business cycle. Toward the end of the recession in mid-2009, however, a discrepancy emerged between the two series: Shimer's measure exhibited a much larger cyclical downturn than the unemployment-to-employment transition rate.

What might account for this anomaly? A natural candidate is suggested by the observation that Shimer's outflow hazard $f_{t}$ captures not only flows from unemployment to employment due to people finding jobs, but also flows from unemployment into nonparticipation. Thus, one might think that the recent deviation in figure 2 reflects a decline in the number of unemployed dropping out of the labor force relative to those finding jobs. In fact, the opposite turns out to be the case. Figure 3 reveals that the flow transition rate from unemployment to nonparticipation has actually increased since the end of the recession, while that to employment has basically been flat. Far from deepening the observed cyclical downturn in the estimated 
Figure 2. Shimer's Outflow Hazard and the Unemployment-to-Employment Transition Probability, 1967-2011 ${ }^{\mathrm{a}}$

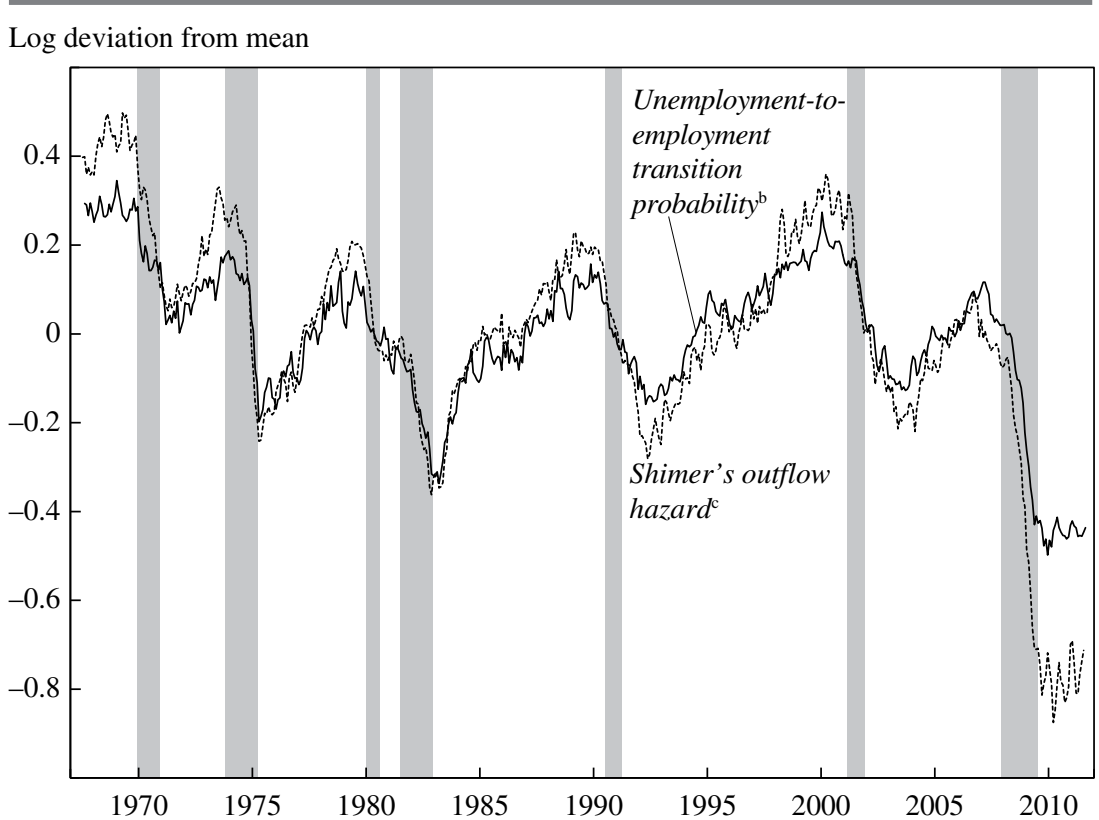

Sources: Shimer (2007); tabulations by Joe Ritter using CPS microdata provided by Hoyt Bleakley; Bureau of Labor Statistics; authors' calculations.

a. Quarterly averages of monthly data. Shading indicates recessions.

b. Percent of unemployed persons flowing into employment, from CPS gross flows.

c. Unemployment outflow hazard calculated using equation 1 in the text.

outflow hazard, this would tend to attenuate its cyclical amplitude relative to the unemployment-to-employment transition rate.

What turns out to be driving the discrepancy is that the outflow hazard is calculated under the natural assumption that everyone who flows into unemployment in a month reports a duration of unemployment of 5 weeks or less. This assumption is not borne out by the data. To see this, consider figure 4 , which shows inflows into unemployment by reported duration as a share of the labor force. Historically, there have always been some inflows into unemployment at reported durations of 5 weeks or longer. Since the start of 2010, however, these inflows have increased in size and now make up about half of the flows into unemployment. A quarter of the total inflows now report durations of at least 6 months. Although in principle these flows should not exist, the reason they appear in the CPS can be traced to the way the survey records unemployment duration. In particular, nothing 
Figure 3. Probabilities of Transition from Unemployment to Employment and to Nonparticipation, 1967-2011

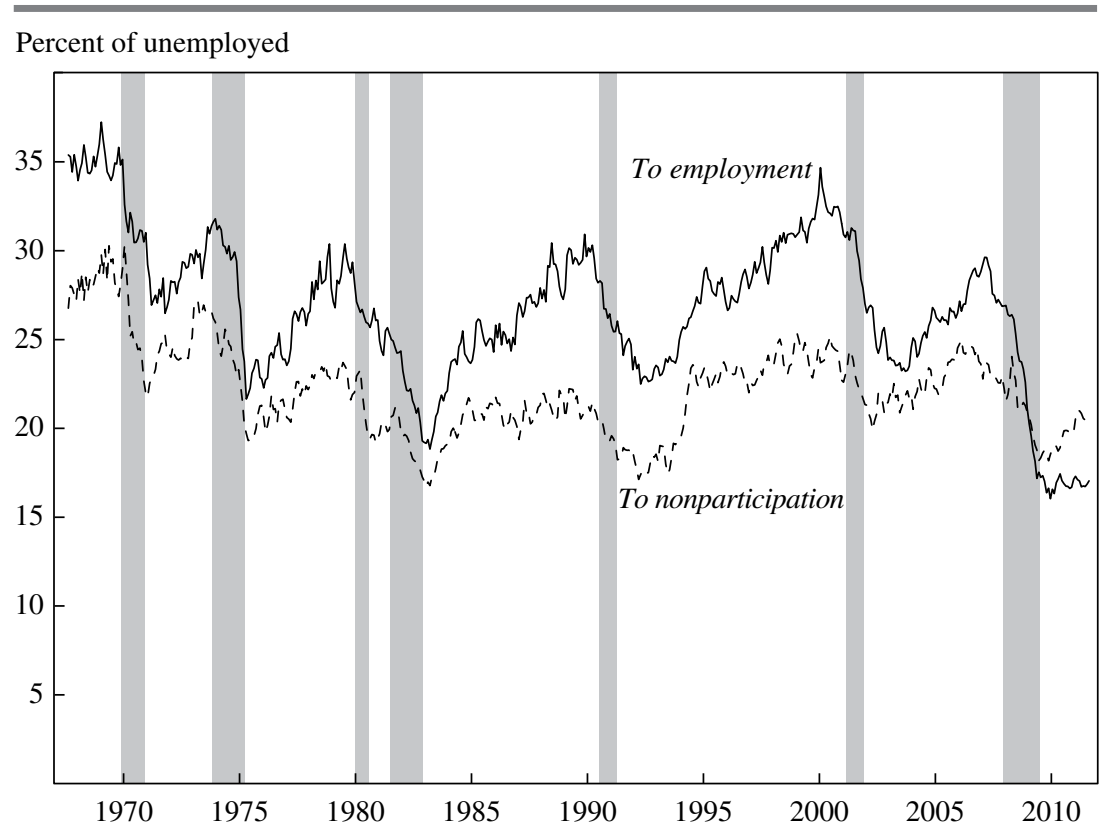

Sources: Shimer (2007); tabulations by Joe Ritter using CPS microdata provided by Hoyt Bleakley; Bureau of Labor Statistics; authors' calculations.

a. Three-month moving averages of seasonally adjusted monthly data. Shading indicates recessions.

in the survey ensures that those who report that they are unemployed today, but who were not classified as unemployed in the previous month's survey, report a duration of unemployment of less than 5 weeks. As a result of these long-duration inflows, total inflows into unemployment exceed $u_{t+1}^{<5 w}$ in the longitudinally matched data, particularly since 2010 . Consequently, Shimer's estimate of the outflow hazard has shown more of a cyclical decline than the outflow probabilities calculated based on BLS (2008). ${ }^{3}$

There are a number of potential interpretations of this phenomenon. A natural candidate is that it reflects random measurement errors, either in labor force status, unemployment duration, or both (Poterba and Summers 1995). Applying this interpretation, however, requires ignoring the clear

3. By the same token, the measure of the inflow rate into unemployment proposed by Shimer (2007), and used by us in Elsby and others (2010), also misses these long-duration inflows into unemployment, since it is also based on the number unemployed for less than 5 weeks. Consistent with this, figure A4 in the online appendix shows that this measure of the inflow rate has reverted completely to its prerecession level. 
Figure 4. Duration Composition of Inflows into Unemployment ${ }^{\mathrm{a}}$

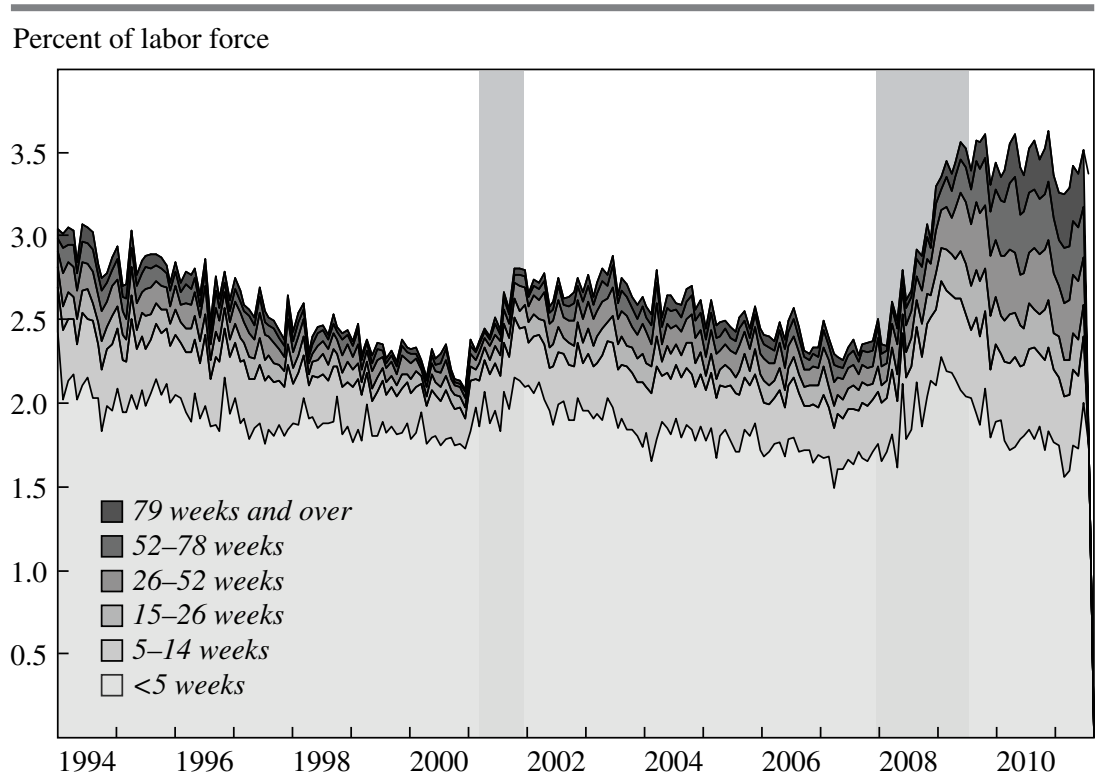

Sources: Bureau of Labor Statistics, Current Population Survey, and authors' calculations. a. Seasonally adjusted monthly observations. Shaded columns indicate recessions.

cyclical pattern reflected in the recent sharp increase in these flows. The cyclical pattern suggests that these inflows may reflect something economically more meaningful about the labor market decisions of CPS respondents than just measurement error. A detailed analysis of who makes up these inflows at long durations is beyond the scope of this update, but a couple of points are worth noting.

First, whereas approximately 60 percent of the inflows into unemployment at reported durations longer than 1 month originate from nonparticipation, only 25 percent of the inflows with duration less than 1 month originate from nonparticipation. These figures suggest that the majority of the long-duration inflows into unemployment are individuals who stopped looking for work for some months and then started looking again in the survey month. ${ }^{4}$ When asked how long they have been looking for a job, it is quite plausible that they would report how long it has been since they initially started looking, rather than when they resumed their search. Like-

4. This is also consistent with the observation that nonparticipants have continued to flow into unemployment at an increasing rate since the end of the recession. See figure A5 in the online appendix. 
wise, employment-to-unemployment flows at long durations are possible for individuals who took on a temporary or part-time job and continued looking for a better job while working.

Thus, one interpretation of these long-duration inflows is that they represent individuals who would like to work more but are not able to find jobs to their liking. Under this interpretation, for those flowing in from employment, the lack of jobs has led them to commit to a temporary solution while continuing to seek better opportunities, whereas for those flowing in from nonparticipation, the lack of jobs has reduced their search effort. The latter group could be reasonably considered as behaving as marginally attached to the labor force.

This brings us to the second aspect of these long-duration inflows that is worth noting. The vast majority of those flowing in from nonparticipation and reporting durations in excess of 1 month were not classified as marginally attached when they were out of the labor force. As noted above, the increased incidence of these long-duration inflows since the recession ended suggests that this pattern does not solely reflect random measurement error, but instead reflects periodic reentry by individuals who are loosely attached to the labor market. If this interpretation is correct, it suggests that alternative measures of unemployment that include the marginally attached, such as the BLS's U5 and U6 measures, have been understating the actual amount of labor underutilization since the recession ended.

The pattern of inflows into unemployment at reported durations exceeding 1 month that we have uncovered is not only important for understanding the anomalies that have recently emerged in estimates of unemployment flows, but indeed essential for understanding the dynamics of the duration distribution of unemployment and thus the dynamics of the long-term unemployment rate. We turn to this issue in the next section.

\section{Long-Term Unemployment: Amerisclerosis?}

In Elsby and others (2010) we presented a simulation of the future path of the aggregate outflow rate that accounted for flow rates out of unemployment that vary substantially by duration. That simulation did not account for the inflows at long durations that have become increasingly prominent since then. ${ }^{5}$ Because these inflows raise measured unemployment durations, ignoring them makes it very difficult to match the right tail of the

5. Other recent analyses that examine the duration distribution of unemployment and duration dependence in exit rates either do not account for the duration structure of inflows (for example, Hornstein 2011) or only partially account for them (for example, Rothstein, this volume). 
Figure 5. Probabilities of Transition from Unemployment to Employment and to Nonparticipation, by Unemployment Duration, July 2010-June 2011

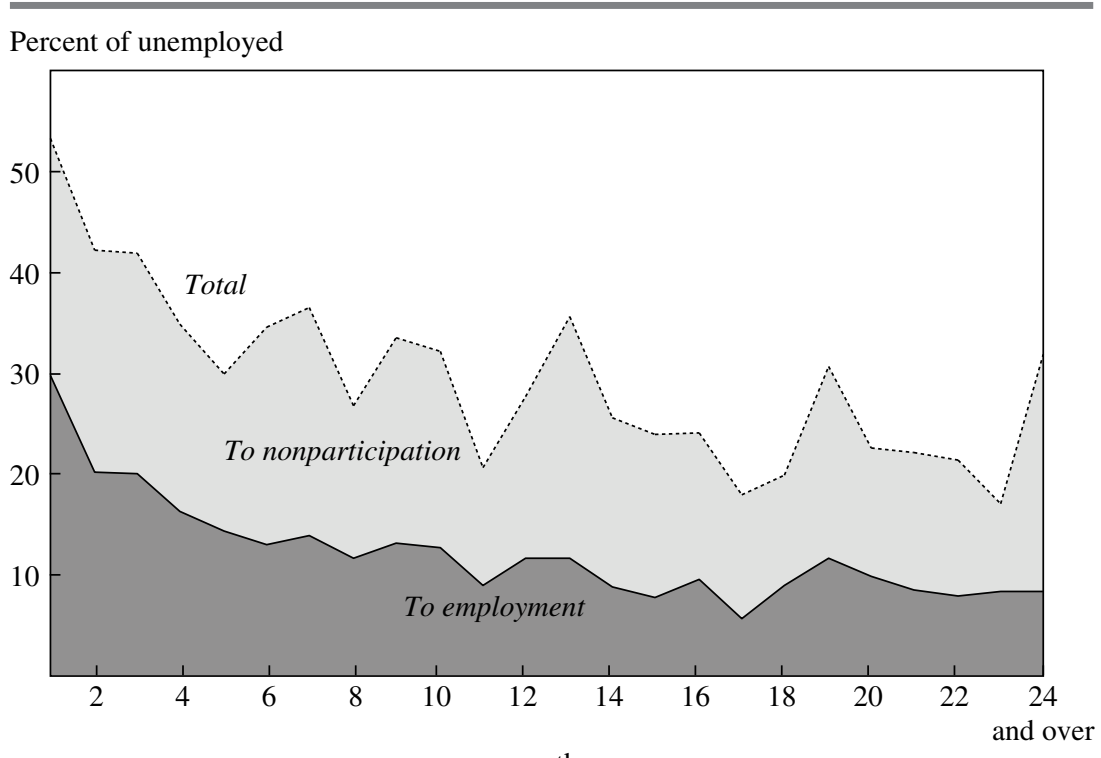

months

Sources: Current Population Survey and authors' calculations.

a. Average for all unemployed workers observed in the matched monthly samples during the period, by indicated duration.

unemployment duration distribution. Although the emphasis in our simulation was not on the duration distribution, it substantially underpredicts the number unemployed at durations of 6 months or longer in the data.

In order to simulate accurately the dynamics of the measured duration structure of unemployment, then, one needs to take into account both inflows and outflows into unemployment at all durations. Figure 4 has already summarized the duration structure of inflows into unemployment. Figure 5 plots estimates of outflow rates from unemployment by duration and destination (employment or nonparticipation) based on CPS microdata for the period from July 2010 through June 2011.

Recent anecdotal evidence suggests that it is very difficult for the longterm unemployed to find a job. ${ }^{6}$ Yet despite the recent severity of long-

6. Catherine Rampell ("The Help-Wanted Sign Comes with a Frustrating Asterisk," New York Times, July 25, 2011), for example, discusses the phenomenon of job ads that explicitly require candidates to be "currently employed" or "recently unemployed." This anecdotal evidence provides support for theories of unemployment dynamics in which applicants are ranked based on their unemployment duration (see, for example, Blanchard and Diamond 1994). 
term unemployment, job finding rates among the long-term unemployed (defined as those with durations exceeding 6 months) remain sufficiently high that most will find work within several months to a year. Figure 5 shows that each month an average of nearly 11 percent of the long-term unemployed find a job. Although this rate of job finding represents a historical low for the United States, it is slightly higher than the outflow rate of the French unemployed, averaged across the complete duration distribution as well as across expansions and recessions (Hobijn and Şahin 2009). At this rate, about half of the long-term unemployed in the United States will find a job within 6 months, and three-fourths will find a job within 1 year.

Figure 5 also reveals that although job finding rates for the longterm unemployed are much lower than for the short-term unemployed, they change little as duration lengthens beyond 6 months. The job finding rate for the very long term unemployed, those with durations of 18 months and higher, is not much lower than for those with durations of 6 to 18 months.

The dynamics of the unemployment duration distribution are determined by the net outflow rates from unemployment (outflows, from figure 5, net of inflows, from figure 4) within different duration ranges. For example, the net outflow rate during a given quarter for durations of 1 to 3 months is given by the share of those unemployed for 1 to 3 months who have not exited unemployment by the next quarter: ${ }^{7}$

$$
f_{t}^{1-3 m}=1-\left(u_{t+1}^{4-6 m} / u_{t}^{1-3 m}\right) .
$$

The calculation of these net outflows is quite simple, since it involves only counting unemployed individuals by duration range and thus does not require the use of longitudinally matched CPS data. This approach assumes that the reported durations are correct, which is appropriate for an exercise aimed at reproducing the duration distribution. ${ }^{8}$

To consider how persistent the long-term unemployment problem in the United States might be, in table 2 we use these flow rates to construct three simulated paths of the unemployment rate. All three paths start with

7. For the rest of our analysis we use quarterly data, because some of the monthly data turn out to be very noisy. The duration ranges we consider are 1 to 3,4 to 6,7 to 9,10 to 12 , 13 to 15,16 to 18 , and more than 18 months.

8. All net outflow rates, except that for durations of 16 to 18 months, are lower in the most recent 4 quarters than before the recession. For some duration ranges, net outflow rates are negative, indicating that inflows exceed outflows. 
Table 2. Simulated Paths of the Unemployment Rate and the Long-Term Unemployment Rate

\begin{tabular}{|c|c|c|c|}
\hline \multirow[b]{2}{*}{ Quarter } & \multicolumn{3}{|c|}{ Simulation } \\
\hline & $2010-11^{\mathrm{a}}$ & Expansion $^{\mathrm{b}}$ & $\begin{array}{c}\text { Structural } \\
\text { unemployment }\end{array}$ \\
\hline \multicolumn{4}{|c|}{ Unemployment rate } \\
\hline 2013Q4 & 9.4 & 5.3 & 6.3 \\
\hline 2014Q4 & 9.5 & 5.2 & 6.1 \\
\hline 2015Q4 & 9.5 & 5.1 & 6.0 \\
\hline Long run & 9.5 & 5.0 & 5.9 \\
\hline \multicolumn{4}{|c|}{ Long-term unemployment rate ${ }^{\mathrm{d}}$} \\
\hline 2013Q4 & 4.4 & 1.4 & 2.4 \\
\hline 2014Q4 & 4.4 & 1.2 & 2.2 \\
\hline 2015Q4 & 4.4 & 1.2 & 2.1 \\
\hline Long run & 4.4 & 1.1 & 1.9 \\
\hline
\end{tabular}

Sources: Authors' calculations.

a. Net outflow rates from unemployment are assumed to remain the average level that prevailed during 2010Q3-2011Q2.

b. Net outflow rates are assumed to return immediately to the average level that prevailed during 2004Q1-2007Q1.

c. Inflows into unemployment and the net outflow rate of the short-term (less than 6 months) unemployed are assumed to return to their 2004Q1-2007Q1 average, but net outflow rates for the long-term unemployed remain at their 2010Q3-2011Q2 average.

d. Persons unemployed for 6 months or longer as a percent of the labor force.

the average duration structure of unemployment and the unemployment rate observed in the most recent data, those for 2011Q2. The first path, "2010-11," is simulated under the assumption that the net outflow rates will remain at the levels that prevailed in the most recent 4 quarters of data. The second path, "Expansion," is simulated under the assumption that net outflow rates return immediately to the levels that prevailed during the preceding expansion, covering 2004Q1-2007Q1.

Of greatest interest is the final path in table 2, labeled "Structural unemployment." This reports results of a counterfactual experiment that provides some perspective on the possible effects of a recovery in labor demand for the short-term unemployed only. We assume here that both inflows into unemployment and the net outflow rates of the short-term unemployed (those with duration less than 6 months) return to their average in the 2004-07 expansion. The demand for long-term unemployed workers, however, is assumed not to recover-their net outflow rates remain at their 2010-11 levels. This counterfactual simulation corresponds to a scenario in which the long-term unemployed are essentially stuck at their existing, depressed rates of exit from unemployment, consistent with the notion that 
their current status reflects structural unemployment that will not dissipate as aggregate labor demand recovers.

Table 2 reports the three paths for the unemployment rate and the long-term unemployment rate obtained from these simulations. The "long-run" values correspond to the implied flow-steady-state outcomes; the unemployment rates listed for prior years converge quickly to the steady-state values. As can be seen from the table, the net outflow rates observed over the past 4 quarters imply a steady-state unemployment rate of 9.5 percent, slightly above that in 2011Q2. Since this " 2010 11 " scenario suggests that the labor market is approximately in its flow steady state, it implies that the long-term unemployment rate will barely budge going forward.

If instead the inflow and net outflow rates were to return instantaneously to their 2004-07 expansion levels, the unemployment rate would drop rapidly to below 6 percent in mid-2012 and 5.1 percent at the end of 2015 and converge to 5.0 percent. Interestingly, the last figure corresponds to a leading current estimate of the prerecession natural rate (Congressional Budget Office 2011). Under this scenario, the long-term unemployment rate drops rapidly to 1.2 percent, which is 0.2 percentage point above its average over the 2004-07 labor market expansion.

It is the "Structural unemployment" exercise, however, that is most informative regarding the factors that are likely to shape the recovery of the labor market. In this scenario in which net outflow rates remain unchanged for the long-term unemployed, the unemployment rate falls steeply to 6.0 percent by the end of 2015 and ultimately converges to 5.9 percent - a rate that falls within the range for the natural rate recently estimated by Daly and others (forthcoming). The relatively modest increase in the steady-state unemployment rate relative to its values in the 2004-07 expansion emphasizes the critical role of improvement in outflow rates for the short-term unemployed for lowering the overall unemployment rate. Strikingly, even though the structural unemployment scenario assumes no improvement in demand for the long-term unemployed, their unemployment rate falls to 1.9 percent, less than half of its value implied by current unemployment flows.

This exercise highlights two important lessons for the recovery of the labor market. First, a very effective way to prevent a long-term unemployment problem is to improve the likelihood that individuals find a job before they become long-term unemployed. Second, even in the context of the very depressed labor market conditions of recent years, the long-term unemployed are nonetheless finding jobs at a sufficient rate that a stimulus 
to the prospects of the short-term unemployed would fuel a rapid and nearcomplete recovery in the labor market as a whole. ${ }^{9}$

\section{Conclusion}

Since our original paper, many other studies have confirmed that there is little evidence that increases in labor market frictions due to mismatch or the effects of the temporary extensions of unemployment compensation can account for a large part of the continued elevated level of unemployment. Instead, downward revisions of data on economic activity released since our original analysis suggest that the labor market weakness is more in line with overall economic slack than we initially thought.

Because of this continued weakness, a record number of the unemployed now report that they have been looking for a job for 6 months or longer. Recently measured unemployment durations have been propped up to an unusual degree by inflows to unemployment at reported durations exceeding 1 month. These inflows are typically ignored in the existing literature on unemployment duration dynamics but are essential to understanding the current environment. In addition, we find that during the last year, over 10 percent of the long-term unemployed have found jobs each month, but this pace has not been rapid enough to reduce reported durations in the presence of the long-duration inflows.

We have used this information on the inflow and outflow rates at different durations to simulate the path of the unemployment rate under alternative scenarios for net outflow rates. We find that even if exit rates for the long-term unemployed do not rise above their recent depressed values, an increase in exit rates for the short-term unemployed to their prerecession levels will substantially reduce the long-term unemployment rate. Hence, we interpret the current flow dynamics of the U.S. labor market as indicating a low risk that the labor market will suffer a bout of Amerisclerosis, or persistently elevated long-term unemployment, even in the wake of the most severe recession in postwar history.

9. This insight regarding the overwhelming importance of exit rates for the short-term unemployed is not new. For example, Nickell (1997) emphasizes this point when he discusses the importance of active labor market policies to aid the unemployed in European countries that did not suffer much from Eurosclerosis. Of course, active labor market policies are only one policy option to improve labor market outcomes of the short-term unemployed. Other types of stimulus might have a similar effect. 
ACKNOWLEDGMENTS The views expressed in this paper solely reflect those of the authors and not necessarily those of the Federal Reserve Bank of New York, the Federal Reserve Bank of San Francisco, or the Federal Reserve System as a whole. We thank Katherine Kuang, Joyce Kwok, and Brian Lucking for their outstanding research assistance. We are especially grateful to Mary Daly, Chris Nekarda, Betsey Stevenson, and Kei-Mu Yi for their helpful suggestions and comments. This version is based on data through September 15,2011 . The authors have no conflicts of interest to report. 


\section{References}

Aaronson, Daniel, Bhashkar Mazumder, and Shani Schechter. 2010. "What Is behind the Rise in Long-Term Unemployment?" Federal Reserve Bank of Chicago Economic Perspectives 2Q: 28-51.

Abraham, Katharine G., and Lawrence F. Katz. 1986. "Cyclical Unemployment: Sectoral Shifts or Aggregate Disturbances?" Journal of Political Economy 94, no. 3: 507-22.

Barnichon, Regis, and Andrew Figura. 2011. "What Drives Matching Efficiency? A Tale of Composition and Dispersion." Finance and Economics Discussion Series no. 2011-10. Washington: Board of Governors of the Federal Reserve System.

Barnichon, Regis, Michael Elsby, Bart Hobijn, and Ayşegül Şahin. 2010. "Which Industries Are Shifting the Beveridge Curve?" Working Paper no. 2010-32. Federal Reserve Bank of San Francisco.

Blanchard, Olivier J., and Peter Diamond. 1994. "Ranking, Unemployment Duration and Wages." Review of Economic Studies 61, no. 3: 417-34.

Bureau of Labor Statistics. 2008. "Research Series on Labor Force Status Flows from the Current Population Survey." www.bls.gov/cps/cps_flows.htm (last accessed September 29, 2011).

Congressional Budget Office. 2011. "Budget and Economic Outlook: An Update." Washington (August).

Daly, Mary, Bart Hobijn, Ayşegül Şahin, and Robert G. Valletta. Forthcoming. "A Rising Natural Rate of Unemployment: Transitory or Permanent?" Journal of Economic Perspectives.

Elsby, Michael W. L., Bart Hobijn, and Ayşegül Şahin. 2010. “The Labor Market in the Great Recession." BPEA (Spring): 1-48.

Estevão, Marcello, and Evridiki Tsounta. 2011. "Has the Great Recession Raised U.S. Structural Unemployment?" Working Paper no. 11/105. Washington: International Monetary Fund.

Farber, Henry S., and Robert G. Valletta. 2011. "Extended Unemployment Insurance and Unemployment Duration in the Great Recession: The U.S. Experience." Federal Reserve Bank of San Francisco and Princeton University (June).

Fujita, Shigeru. 2011. "Effects of the UI Benefit Extensions: Evidence from the Monthly CPS.” Working Paper no. 10-35. Federal Reserve Bank of Philadelphia (January).

Hobijn, Bart, and Ayşegül Şahin. 2009. "Job Finding and Separation Rates in the OECD." Economics Letters 104: 107-11.

Hornstein, Andreas. 2011. "Accounting for Unemployment: The Long and Short of It." Federal Reserve Bank of Richmond.

Kaplan, Greg, and Sam Schulhofer-Wohl. 2010. "Interstate Migration Has Fallen Less than You Think: Consequences of Hot Deck Imputation in the Current Population Survey." Federal Reserve Bank of Minneapolis.

Kocherlakota, Narayana. 2010. "Inside the FOMC.” Speech at Northern Michigan University, Marquette, August 17. 
Molloy, Raven, Christopher L. Smith, and Abigail Wozniak 2010. "Internal Migration in the US: Updated Facts and Recent Trends." Washington: Board of Governors of the Federal Reserve System.

Nakajima, Makoto. 2011. "A Quantitative Analysis of Unemployment Benefit Extensions." Working Paper no. 11-8. Federal Reserve Bank of Philadelphia.

Nickell, Stephen. 1997. "Unemployment and Labor Market Rigidities: Europe versus North America." Journal of Economic Perspectives 113: 55-74.

Perry, George L. 1972. "Unemployment Flows in the U.S. Labor Market." BPEA, no. 2: 245-78.

Poterba, James M., and Lawrence H. Summers. 1995, "Unemployment Benefits and Labor Market Transitions: A Multinomial Logit Model with Errors in Classification." Review of Economics and Statistics 77: 207-16.

Şahin, Ayşegül, Joseph Song, Giorgio Topa, and Gianluca Violante. 2011. "Measuring Mismatch in the U.S. Labor Market." Federal Reserve Bank of New York and New York University.

Shimer, Robert. 2005. "The Cyclical Behavior of Equilibrium Unemployment and Vacancies." American Economic Review 95: 25-49.

. 2007. "Reassessing the Ins and Outs of Unemployment." Working Paper no. 13421. Cambridge, Mass.: National Bureau of Economic Research.

2008. "The Probability of Finding a Job." American Economic Review 98, no. 2: 268-73.

Valletta, Robert G. 2010. "House Lock and Structural Unemployment." Federal Reserve Bank of San Francisco.

Valletta, Robert G., and Katherine Kuang. 2010. "Extended Unemployment and UI Benefits.” Economic Letter 2010-12. Federal Reserve Bank of San Francisco. 


\section{Comment and Discussion}

\section{COMMENT BY}

BETSEY STEVENSON and ANDREW LANGAN Michael Elsby, Bart Hobijn, Ayşegül Şahin, and Robert Valletta have provided a superb update to earlier research by the first three authors documenting the worst labor market downturn since the Great Depression. In their original Brookings Paper (Elsby and others 2010), they showed that the Great Recession was significantly deeper than other postwar recessions and that the magnitude of the labor market downturn was even larger than would have been predicted given the decline in GDP. They also found that despite the unusual depth of this recession, the demographic composition of the labor market adjustment was similar to that in past recessions-contrary to claims in the popular press of a "mancession" and an "unprecedented" rise in unemployment among white-collar workers. ${ }^{1}$ Moreover, they found that the pattern of inflows and outflows early in the downturn was typical of that in past recessions, with a sharp rise in unemployment inflows from layoffs followed by a large decline in unemployment outflows, which in this episode reached a postwar low. However, they argued that the sustained high unemployment rates in late 2009 and early 2010 - attributable to continued low outflows from unemployment—suggested a shift of the Beveridge curve and a new, higher natural rate of unemployment.

In this update of that 2010 Brookings Paper, Elsby and his coauthors show, first, that subsequent data revisions have altered views of the Great Recession. The decline in GDP was much greater than previously thought, and hence the large deterioration in labor market conditions was more in

1. See, for example, Derek Thompson, "It's Not Just a Recession. It's a Mancession!" The Atlantic, July 9, 2009, and Patrick McGeehan, "This Time, Slump Hits Well-Educated, Too," The New York Times, April 4, 2009. 
line with Okun's Law. Data revisions also shrank the perceived shift of the Beveridge curve, which had partly reflected an inflated estimate of vacancies.

Second, the authors marshal evidence suggesting that housing market malaise, skills mismatch, and relatively generous unemployment insurance benefits are unlikely to lead to persistently higher unemployment, and thus there is little evidence of structural unemployment problems. Third, they revisit the labor market flow data to see what has changed. In doing so, they uncover new puzzles in the data, reflecting the fact that employment status and unemployment duration are self-reported. After accounting for these puzzles, the authors update the simulation of unemployment dynamics presented in the earlier work, finding that the U.S. labor market is unlikely to suffer from the persistently high long-term unemployment rates that dogged Europe in the 1970s and 1980s. Finally, the authors examine the recent labor market experiences of different demographic groups, finding that those groups that suffered the largest increase in unemployment have subsequently experienced relatively larger declines in unemployment. In all, the authors are quite optimistic about the future prospects of the U.S. labor market.

In this comment we will seek to temper this optimism by highlighting some of the areas of potential concern for the labor market going forward. The first of these is the challenge of correctly assessing the job prospects of the unemployed, given the problems the authors identify with the unemployment duration data. The second area of concern involves changes in labor force participation. The authors highlight declines in unemployment, but employment-to-population ratios show that the labor market had yet to begin its recovery in the period they examine. This affects the authors' simulation results as well, as they do not assume that labor force participation rates return to their prerecession levels, but do assume that transitions out of the labor force continue at either current or prerecessionary levels; thus, part of the fall in long-term unemployment in their expansion scenario comes as people stop looking for work. A third concern is the fact that some groups - women, older workers, and blacks—have had a particularly hard time in this recovery, as is evident both in employment-to-population ratios and in labor market flows broken down by demographic characteristics. A fourth is that public sector budget cuts are causing ongoing public sector job loss. A final concern has to do with job mobility. In their discussion of geographic mismatch of jobs with workers, the authors, like others, focus only on the housing market. It may be that geographic mismatch is playing a role, but that the relevant frictions are family dynamics and the 
challenges faced by dual-career couples. Too little research has considered the coordination issues inherent in job mobility among couples. We will elaborate on each of these points in turn.

MEASURING UNEMPLOYMENT DURATION AND ASSESSING REEMPLOYMENT The authors' analysis of the longitudinal aspect of the Current Population Survey (CPS) yields a finding that is also reported by Jesse Rothstein in this volume: the month-to-month flow data appear to be overstating the amount of churn in the labor market and do not generate the unemployment durations observed in the monthly cross section. To understand this problem, one needs to start with the definitions of unemployment and unemployment duration: the unemployed are those who are available for, and actively seeking, work; unemployment duration measures the length of time that people spend continuously in this state. The assumption that most economists make when working with the data is that people respond to the CPS in a manner consistent with these definitions. Perhaps more important, they assume that people's responses do not systematically deviate from these definitions in a way that is correlated with the business cycle. Yet the authors find that, in the wake of the recent recession, a larger share of respondents' reported durations of unemployment deviate from the official definition. A substantial number of the newly unemployed report unemployment durations of over 5 weeks, despite having reported in the preceding month's interview that they were employed or out of the labor force. Many of them even report durations of over 6 months, thus adding themselves to standard measures of long-term unemployment. This finding adds a new dimension to understanding the unprecedented rise in unemployment duration. More generally, it reminds us that the borders between labor market statuses are fuzzier than our definitions imply.

This measurement problem can also lead analysts to overstate the chances that the long-term unemployed will find stable employment. For instance, the authors calculate the month-to-month flows from unemployment to employment using the longitudinal aspect of the CPS and conclude that "three-fourths [of the long-term unemployed] will find a job within 1 year." However, their analysis suggests that this estimate includes a lot of spurious or temporary employment spells that disappear by the next month, and they therefore use flows calculated from the cross section in conducting their simulations. These data suggest that perhaps only about 35 to 40 percent of the long-term unemployed exit to employment within a year. The longitudinal data also provide another perspective when examined over a longer time frame: among those CPS respondents who reported being unemployed in the fall of 2010, only around 
40 percent reported being currently employed 1 year later, and even fewer of those who were long-term unemployed in the fall of 2010 were working a year later. Although this exercise is subject to many caveats-not all people can be matched 12 months later, and those who report being unemployed in both periods may have had, and then subsequently lost, employment over the course of the intervening year-the results show that the job prospects of the unemployed are far worse than the monthly flow estimates suggest.

FALLING LABOR FORCE PARTICIPATION WITH NO IMPROVEMENT IN EMPLOYMENT The primary importance of flows out of low-duration unemployment for determining steady-state unemployment rates is part of the reason that Elsby and his coauthors (2010) concluded that there was little likelihood of a Eurosclerosis-like problem in the United States. However, their analysis does not preclude the emergence of a large segment of the population dropping out of the labor force. In all recessions, labor force participation declines, and the recent recession and its aftermath have been no exception. Our table 1 shows that the labor force participation rate fell 1.1 percentage points during the recession and that it declined an additional 0.8 percentage point between 2009Q4 and 2011Q2. Participation continued to decline by another 0.1 percentage point in the second half of 2011 .

These declines in the labor force are largely responsible for the decline in the unemployment rate during the recovery through 2011Q2. Meanwhile the employment-to-population ratio fell 4.6 percentage points during the recession and another 0.1 percentage point in the same recovery period. Although unemployment started to decline following its October 2009 peak, the employment-to-population ratio remained at its recession low in 2011Q3. Since then it has recovered slightly, rising 0.3 percentage point above its recession low by the end of 2011 and by another 0.3 percentage point in January 2012. ${ }^{2}$ These rates show that the labor market began to turn around only in 2011Q4. Thus, unemployment fell in the period analyzed by the authors only because labor force participation fell. More generally, the prospects for labor force recovery are a function of both labor force participation trends and unemployment.

ONGOING CHALLENGES FOR SOME DEMOGRAPHIC GROUPS The employmentto-population ratios in table 1 also show pronounced differences in labor

2. The reported employment-to-population ratio was unchanged between December and January as the January 2012 rate reflected a reweighting of the population to take into account the 2010 census findings. This reweighting lowered the employment-to-population ratio by 0.3 percentage point as the population was found to be older than previously estimated. 


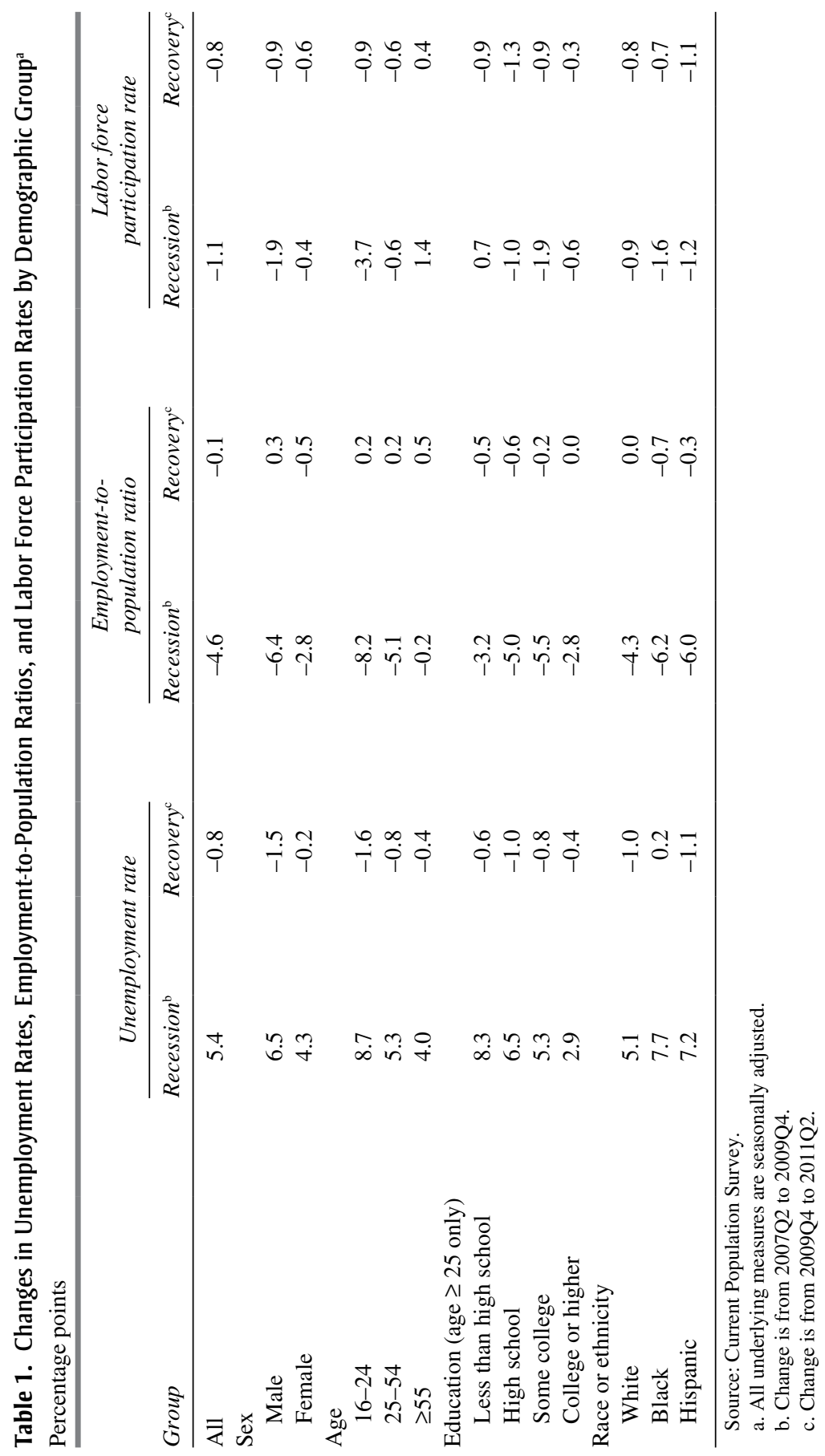


market recovery across groups. Although both men's and women's unemployment rates have improved during the recovery, employment has continued to decline among women while increasing among men. Labor force participation rates for both men and women have continued to decline. Examining labor market flows by sex shows that the different experiences of men and women in the recovery partly reflect a continuing decline in flows from unemployment to employment for women and an improvement for men. In short, men have started finding jobs, while women's job prospects have continued to deteriorate.

The breakdown by education in table 1 shows that employment has fallen in the recovery period for all but college-educated workers and that less educated workers have suffered bigger declines in labor force participation. Employment rates have improved for whites during the recovery but continued to decline among minorities. In sum, unlike unemployment rates, the changes in the employment-to-population ratios show no evidence that the labor market is improving for groups worse hit by the recession. The fact reported by the authors - that the groups with the largest increases in unemployment during the recession have had relatively larger declines in unemployment in the recovery-is driven largely by relatively larger declines in labor force participation for these groups.

However, some of the aggregate decline in the employment-to-population ratio in the recovery is a function of changing demographics. Examining employment rates by age shows small increases within each group. However, the continuing decline in employment for women occurred for all women under age 55. Similarly, the employment rate of prime-age blacksthose aged 25 to 54-fell through the middle of 2011. Moreover, among all workers under 55, labor force participation fell in the recovery period through 2011Q2. In contrast, participation increased among those over 55. Yet the low unemployment rates and rising labor force participation rates of older workers hide unique challenges that older unemployed workers face in finding jobs. Although they are less likely than younger workers to become unemployed, once they do, they have a harder time reentering employment.

Median unemployment duration increased from 8.5 weeks in 2007 to 21.4 weeks in 2011, but underlying this increase is enormous variation by age. Unemployed older workers, regardless of education, had the largest increase in unemployment duration. Workers of all ages experienced large decreases in flows out of unemployment in the early part of the recession, but the difference in unemployment duration by age has widened during the recovery, through a combination of continued declines in unemployment 
Figure 1. Payroll Employment in the Public and Private Sectors, 1964-2011

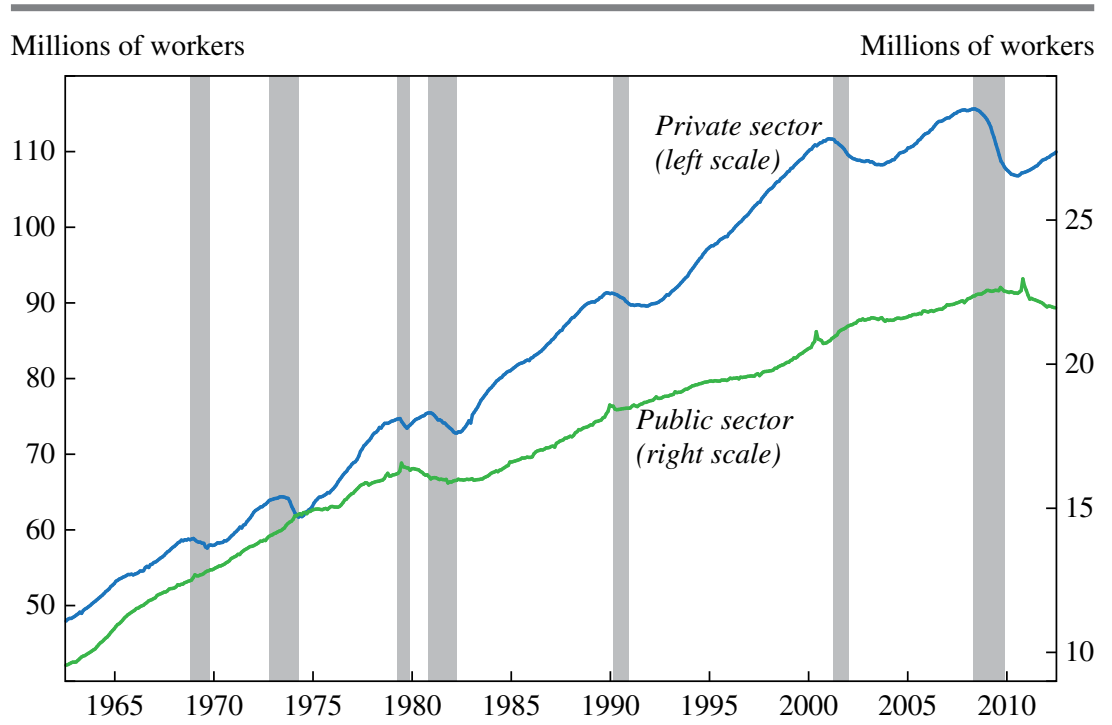

Source: Current Employment Statistics.

a. Data are seasonally adjusted and exclude the effects of decennial census employment. Shading indicates recessions.

outflows for older workers and increasing flows into employment for younger unemployed workers. In short, although long-term unemployment rates may rise only slightly in the long run, as the authors expect, it is likely that older workers will be disproportionately represented among the longterm unemployed.

THE IMPACT OF PUBLIC SECTOR BUDGET CUTS One way in which this recovery differs from previous periods is in the deep cuts to government employment. These began as the recession was officially ending and have continued to the present day. Our figure 1 shows that during most recessions and subsequent recoveries, government employment has continued to grow. In contrast, government employment stopped growing in the middle of 2008 and began to decline in early 2009. As of January 2012, total government employment had fallen 2.6 percent from its December 2008 level, with most of the losses in state and local government, where employment fell 2.6 percent and 3.4 percent, respectively.

Government employment represents approximately one in six jobs. Thus, these large declines in public sector employment are contributing to the slow job growth in the recovery both directly, by offsetting gains in the 
private sector, and indirectly, by hampering the recovery in aggregate demand. But beyond these aggregate effects, the loss of government jobs is hurting some groups more than others. As noted above, women and minorities have continued to experience declines in employment during the recovery. This partly reflects their disproportionate employment in the public sector.

Blacks have been particularly hard hit by the cuts in public sector employment: the share of blacks in the CPS reporting employment in the public sector fell by 6.0 percent between December 2008 and December 2011. In contrast, the share of whites employed in the public sector fell by 4.0 percent over that period. This difference is compounded by the fact that blacks are about a third more likely than whites to work in the public sector, so the higher rate of job loss applies to a larger share of employed blacks.

Similarly, women are more likely than men to work in the public sector, and public sector job losses have been concentrated among female employees, with teachers and low-wage workers bearing a large share of the cuts. For the 3-year period ending in December 2011, data from the Current Employment Statistics show a 3.3 percent decline in government jobs held by women, compared with a 1.7 percent decline for men. CPS data suggest that the job losses were even more concentrated among women: over the same period, the share of women reporting employment in the public sector fell by 5.6 percent, while that for men was 0.8 percent.

GEOGRAPHIC MOBILITY AND THE FAMILY Finally, one aspect of the labor market that deserves greater scrutiny is the challenges that couples face when one of them becomes unemployed. As Elsby and his coauthors note in this update, there is little evidence of a sharp decline in geographic mobility in the current recovery; however, geographic mobility is significantly lower than it was in the 1982 recession and has been trending downward for several decades (Molloy, Smith, and Wozniak 2011). One possibility is that the increasing contribution of wives' earnings to household income is making it ever more difficult for an unemployed married worker to move to take a job opportunity elsewhere. A spouse's job may cause greater geographic lock than the troubles in the housing market. One characteristic of the labor market in the current recovery is low quit rates, and thus fewer employment-to-employment transitions. Given the challenges inherent in finding a new job, employed workers may be unwilling or simply unable to relocate so that their unemployed spouse can take a job elsewhere. This is an area that deserves more research before one can conclude that restricted geographic mobility is not contributing to a slower recovery than occurred following the 1982 recession. 
In conclusion, Elsby and his coauthors have produced a superb analysis of labor market flows and their implications. It has important ramifications for how researchers think about the boundaries between labor market statuses and labor market flows, and the authors use its insights into flow patterns to extrapolate a dynamic by which the unemployment rateboth short-term and long-term-could be reduced, even in the absence of a change to the flow dynamics for the long-term unemployed. However, other unique and troubling aspects of the recent recession have emerged that may cause lingering labor market difficulties in the long run, especially for particular demographic groups. In light of worrying postrecession employment rates and policy gridlock in the nation's capital, the prospects for a robust labor market recovery remain uncertain.

\section{REFERENCES FOR THE STEVENSON AND LANGAN COMMENT}

Elsby, Michael W. L, Bart Hobijn, and Ayşegül Şahin. 2010. “The Labor Market in the Great Recession." BPEA, no. 2: 1-48.

Molloy, Raven, Christopher L. Smith, and Abigail Wozniak. 2011. "Internal Migration in the United States.” Journal of Economic Perspectives 25, no. 3: 173-96.

GENERAL DISCUSSION Justin Wolfers recalled that macroeconomists had spent much of 2009 wondering whether Okun's Law had been repealed, and much of 2010 wondering the same about the Beveridge curve. One thing that this update of the Elsby, Hobijn, and Şahin paper showed was that those economic relationships were still intact but that the data had needed to catch up. Wolfers saw this as a valuable reminder that data are always imperfect and that patterns observed in the past tend to persist.

Wolfers also remarked on the finding that the increasing average duration of unemployment was concentrated among older workers. Although some might see this as a bad thing, he suggested that for those who worry about hysteresis it might actually be good news. The concern had been that the rise in long-term unemployment was concentrated among the youngest workers, some of whom might lose any attachment they had to the labor force and never work again. To the extent that the rise in long-term unemployment was instead occurring among workers in their late 50s and early $60 \mathrm{~s}$, the possibility of their exit from the labor force implied a smaller loss, because they would have retired soon anyway.

Finally, Wolfers was reminded of Robert Hall's comment during the discussion of Jesse Rothstein's paper that proxy responses-that is, persons answering questions about other household members-were a potential 
source of error in the Current Population Survey data. He wondered whether some of the difficulty in accurately distinguishing unemployed workers from persons outside the labor force might be due in part to such proxying. Wolfers further conjectured that proxy responding might rise during a recession, because more household members are likely to be at home when the survey worker calls. The solution, he thought, might be to measure employment and labor force participation using administrative data instead, whether from state unemployment agencies or from the Department of Labor.

Till von Wachter agreed with Wolfers that it was good news that unemployed youth are finding jobs faster than the average, but he cautioned that average unemployment duration was not the only relevant measure. Young workers tend to be more willing to take whatever job comes along, and their wages are more flexible than those of older workers. Thus, in a recession they often take bad jobs at low wages. Of course, they can later work their way up to better jobs and higher wages, but that process would be slow in a weak economy. Conversely, although workers who become unemployed in late middle age suffer smaller lifetime earnings losses than younger workers, the cost to society of their joblessness can still be high if they start receiving social insurance benefits sooner than they would have otherwise.

Also responding to Wolfers, Jesse Rothstein argued that the distinction between unemployed and out of the labor force was fundamentally ambiguous, and that one did not need to invoke proxy responding to explain the fuzziness in the data. In fact, there is no bright line between the two conditions. He offered the following example. The Bureau of Labor Statistics counts an individual as unemployed if he or she has looked for work in the last four weeks. Given that several months might elapse between interviews, a respondent might have been unemployed at the first interview and be unemployed again at the second, and would be counted as continuously unemployed. But suppose that same individual stopped looking for work for a four-week spell in between surveys. Then that individual might be recorded as not continuously unemployed if the interviews were more frequent. In other words, the same nonemployment history could be recorded in different ways depending merely on interview timing. Similarly, Rothstein thought, many of those currently being recorded as reentrants into the labor force were people who a couple of months earlier were unemployed, and it is likely that they think of themselves, quite naturally, as continuously unemployed rather than as reentrants.

Stephanie Aaronson agreed that there was a gray area consisting of people who are available for work and would like to have a job but are not 
actively looking, and thus are not well captured by the usual definitions. Although the CPS had been redesigned in 1994 in an attempt to better capture these marginal workers, it seemed clear that the CPS was still missing them, and missing them in a way that was different from previous cycles.

Laurence Ball asked whether anyone on the Panel could explain, in a simple accounting sense, why long-term unemployment had risen so much from what it had been in the early 1980s - where were the additional longterm unemployed coming from? Betsey Stevenson said that part of the answer was that more of the long-term unemployed are continuing to look for work, and so remain counted as unemployed rather than as exiting the labor force, than in the past. Christopher Nekarda added that in past decades a much larger share of the unemployed were on temporary layoff, and thus more likely to be recalled to their jobs before their unemployment spells became prolonged. Robert Gordon offered a third explanation, namely, that the recovery from the early-1980s recession had been rapid, shortening the average employment spell; in contrast, today's very slow recovery is causing many employment spells to drag on.

Following up on the discussion of Okun's Law, Gordon also offered an update of his own analysis. Okun's Law predicts that a cyclical decline in output will be divided in a two-to-one ratio between a reduction in hours and a reduction in productivity. The actual relationship over the postwar period up to the mid-1980s was about three to one. Since then, however, reductions in hours have more than fully accounted for cyclical declines in output, leaving no role for procyclical productivity fluctuations. Given that change in the relationship, the weakness of the current labor market recovery was no puzzle: the hours gap, at 8 percent, was the same as the output gap. The output gap had hardly narrowed at all in the last 2 years, and therefore, unsurprisingly, neither had the hours gap.

Simon Gilchrist addressed the impact of the housing collapse on labor markets. He found the available evidence fairly persuasive that the decline in housing prices had not increased unemployment by making workers less mobile, stuck in homes that they could not sell for enough to cover their mortgage obligations. He speculated, however, that the housing debacle might have had adverse wealth effects that in turn affected labor market decisions: for example, older workers who had counted on using their homes to fund an early retirement might now be choosing to stay in the labor force and be looking for jobs. One could test that hypothesis by comparing geographic regions to see whether those with the largest housing price declines tended to have a larger increase in the share of older unemployed workers. 
Responding to the discussion, Ayşegül Şahin agreed with Stevenson that the popular characterization of the recent recession as a "mancession" was factually incorrect. Moreover, in the aftermath of the recession, women were faring less well than men, both overall and within industries. She saw several possible explanations for this, all of them speculative. The first started from the fact that, within sectors, some occupations are dominated by men and others by women: it could be that the male-dominated occupations lost jobs disproportionately during the recession and are regaining them disproportionately now. Another possibility, which Mark Aguiar and Erik Hurst had investigated, was that men are more likely to invest in job training while unemployed, whereas women are more likely to engage in home production instead, and this discrepancy could give men an advantage in the job market during a recovery. Finally, it could be that men are more flexible about work schedules - that is, more willing to accept a job that involves other than a 40-hour, 9-to-5 workweek-and that this leads to their being rehired more rapidly than women.

In reply to Wolfers, Şahin agreed that the Beveridge curve was alive and well. She noted, however, that the curve seemed to have rotated counterclockwise, as predicted by the Mortensen-Pissarides model. She also agreed with Rothstein and the other discussants that the distinction between unemployment and nonparticipation was ambiguous and that the BLS's definition of marginal attachment was not adequately capturing workers on the sidelines. Clearly some improvement was needed on these measurement issues, given recent proposals to make certain policies conditional on a given unemployment rate.

Şahin also offered two additional possible explanations, both of which are mentioned in the literature, for why long-term unemployment has increased since the 1980s. One of these was a compositional effect related to von Wachter's point about younger unemployed workers being quicker to take the first job offered: the implication was that older workers tend to have higher unemployment durations, and given that the workforce today is older on average than that of the 1980s, that could contribute to higher long-term unemployment today. The second possibility stemmed from the increase in wage inequality: the rising differences in wages across different jobs might prompt unemployed workers to prolong their job search in the hope of finding a much better paying job than what was immediately on offer.

Finally, replying to Gilchrist, Şahin said her understanding was that most studies did find that negative housing equity reduced the mobility 
of some workers, but on the other hand, those whose homes had already been foreclosed on experienced increased mobility, so that the two effects tended to cancel each other out. She cited work by Raven Molloy, Abigail Wozniak, and Christopher Smith that had found very similar effects on mobility across different states with different home price movements. 